\title{
Surface treatments of indium-tin-oxide substrates: comprehensive investigation of mechanical, chemical, thermal, and plasma treatments
}

\author{
A. B. Djurišić, ${ }^{a}$ T. W. Lau, ${ }^{a}$ C. Y. Kwong, ${ }^{a}$ W. L. Guo, ${ }^{a}$ Y. K. Bai, ${ }^{a}$ E. Herbert Li, ${ }^{a}$ and W. K. Chan ${ }^{b}$ \\ a'Department of Electrical \& Electronic Engineering, University of Hong Kong, \\ Pokfulam Road, Hong Kong \\ ${ }^{b}$ Department of Chemistry, University of Hong Kong, \\ Pokfulam Road, Hong Kong
}

\begin{abstract}
Various surface treatments significantly affect the work function and surface roughness of indium tin oxide (ITO), and thusly influence charge injection and overall performance of organic light emitting diodes (OLEDs). Large number of treatments, most commonly oxygen plasma treatment and UV-ozone treatment, have been proposed to improve characteristics of ITO. In this work, we have investigated a) mechanical treatments (mechanical rubbing, followed by ultrasonic bath), b) chemical treatments (dipping into aqueous solutions of various acids, including acids which have not been investigated previously) c) thermal treatments (thermal annealing in different atmospheres) d) plasma treatments e) UV ozone treatment $f$ ) different combinations of the above. We have measured surface sheet resistance of the samples and investigated surface morphology of the treated samples and compared them to "as-received" samples. We have selected several treatments giving best results. Then we have fabricated OLEDs using ITO substrates treated with treatments selected, as well as a control OLED fabricated on "as-received" ITO. The impact of ITO treatments on the performance of OLEDs have been investigated on two types of devices, OLEDs with and without transport layer, having the structures glass/TTO/Alq $3 / \mathrm{Al}$ and glass/ ITO/TPD/Alq $3 / \mathrm{Al}$, respectively, where $\mathrm{Alq}_{3}$ (tris-(8-hydroxyquinoline) aluminum) is emitting layer and TPD (N,N'-diphenyl-N,N'-bis(3-methyl-phenyl)-1,1'biphenil-4,4'diamine) is a hole transport layer.
\end{abstract}

Keywords: indium-tin-oxide, organic light emitting diodes

\section{INTRODUCTION}

Organic light emitting diodes (OLEDs) are being intensively investigated in terms of efficient materials and device structures for their great potential in the huge display market. Performance of an OLED is highly dependent on the charge injection process. Commonly used hole injection electrode in OLEDs is indium tin oxide (ITO). ITO has low resistivity, can be easily patterned and it is transparent in the visible spectral region. Due to its use in liquid crystal displays, ITO is widely available. The properties of ITO are highly dependent on deposition method (thermal evaporation, sputtering or pulsed laser deposition ) and deposition conditions, as well as various surface treatments of as-grown or as-received (for commercially available ITO substrates) ITO substrates. Work function of ITO can vary from about $4 \mathrm{eV}$ to about $5 \mathrm{eV}$ depending on the surface treatment. An objective of surface treatment would be to achieve the lowest sheet resistance, the lowest surface roughness and high work function. Work function value is particularly important for achieving more efficient hole injection.

In order to achieve highly efficient hole injection, it is necessary to reduce the barrier for injection of holes into the highest occupied molecular orbitals (HOMO) of an organic material. A variety of surface treatments have been proposed in the literature in order to improve efficiency, turn-on voltage, and lifetime of OLEDs. Different plasma treatments have been proposed. ${ }^{1.14}$ Chemical treatments with $\mathrm{HCl}^{13}{ }^{13}$ different acids and bases ${ }^{15,16}$ or aquaregia ${ }^{2-6}$ have been investigated. Other treatments, such as mechanical ${ }^{2,5,13}$ thermal annealing, ${ }^{17-19}$ or UV ozone treatment ${ }^{17,20}$ have also been proposed. It has been demonstrated by Nüesch et al. ${ }^{15,16}$ that work function changes of the order of $1 \mathrm{eV}$ can be induced by treating ITO surface with acids or bases. Treatment with bases reduced the work function, with the lowest value $(3.9 \mathrm{eV})$ obtained with tetrabutylammonium hydroxide $\mathrm{N}\left(\mathrm{C}_{4} \mathrm{H}_{9}\right)_{4} \mathrm{OH}$. Acid treatment increased the work function, with the best results obtained using phosphoric acid $\mathrm{H}_{3} \mathrm{PO}_{4}(5.1 \mathrm{eV})$. All the samples were exposed to oxygen plasma for $5 \mathrm{~min}$ before acid or base

${ }^{*}$ E_mail:dalek@eee.hku.hk 
treatment. ${ }^{15,16}$ No change in work function for dipping in water for $5 \mathrm{~min}$. has been found for both oxygen and argon plasma treatment (average microwave power $200 \mathrm{~W}$, exposure time five minutes). The lowest onset voltage has been obtained for phosphoric acid treated devices, and the highest for tetrabutylammonium hydroxide treated ones. Surprisingly, water dipping caused change in the obtained onset voltage (shift to higher value) in spite of no change observed in the work function. Nüesch et al. ${ }^{15,16}$ have not investigated influence of the chemical treatments to sheet resistance and surface morphology.

Kim et al. ${ }^{2-8}$ have performed comprehensive investigation of the influence of various treatments (mechanical, oxygen plasma, argon plasma, aquaregia $\left(\mathrm{HNO}_{3}: \mathrm{HCl}: \mathrm{H}_{2} \mathrm{O}\right.$ 1:3:20), and RCA protocol $\left(\mathrm{NH}_{3}: \mathrm{H}_{2} \mathrm{O}_{2}: \mathrm{H}_{2} \mathrm{O}\right.$ 1:4:20)). They have found that mechanical rubbing (paper or teflon) slightly reduces the work function, as well as RCA protocol and ultrasonic cleaning. Aquaregia treatment and oxygen plasma can either reduce or increase the work function, depending on the treatment time. ${ }^{5}$ Argon plasma treatment has very small influence on the work function, slightly increases sheet resistance and greatly increases the surface roughness of ITO substrates ${ }^{5}$ and hence can be considered as ineffective treatment for the improvement of the performance of OLEDs. Sheet resistance was reduced only for 10 minutes oxygen plasma treatment and wet ultrasonic cleaning, while surface roughness has been reduced by mechanical rubbing, RCA treatment, oxygen plasma, and oxygen plasma followed by aquaregia. ${ }^{5}$ For combined oxygen plasma/aquaregia treatments, order of treatment (oxygen plasma first, or aquaregia first) significantly influenced the obtained result. Kim et al. ${ }^{2-8}$ therefore propose oxygen plasma for 10 minutes as the best treatment of ITO anodes for OLEDs applications. Oxygen plasma treatment has been found to lead to increase in carrier concentration and decrease in mobility, resulting in overall decrease in resistivity. ${ }^{3}$ Oxygen plasma treatment did not etch the ITO surface and did not lead to formation of hydroxide layer on the surface, while both oxygenplasma/aquaregia and aquaregia/oxygen plasma treatments etched the surface and caused formation of a thin metal hydroxide rich layer on the surface. ${ }^{6}$ This is in agreement with the study of Nüesch et al. ${ }^{16}$

Increase in the work function of ITO after oxygen or air plasma treatment compared to argon plasma treatment (small decrease or insignificant change in the work function) has been confirmed by other authors as well., ${ }^{9}$ Recently, high work function value of $6 \mathrm{eV}$ has been reported for Ar-50\% $\mathrm{O}_{2}$ plasma treatment performed after UV ozone treatment. ${ }^{14} \mathrm{Another}$ recent work has found that $\mathrm{SF}_{6}$ plasma treatment enables obtaining better OLED performance compared to oxygen plasma treated one. ${ }^{1}$ This improvement has been attributed to the surface incorporation of fluorine. ${ }^{1}$ Fujita et al. ${ }^{13}$ have also obtained increase in the work function $\left(1.2 \mathrm{eV}\right.$ increase) after oxygen plasma treatment. However, Fujita et al. ${ }^{13}$ report that the oxygen plasma treated ITO has highest sheet resistivity, which is in contradiction with the results of Kim et al. ${ }^{3-5}$ who found that oxygen plasma treatment lowers the sheet resistance. Fujita $e t$ al ${ }^{13}$ also report no change in the work function for mechanical rubbing and dipping in $7 \% \mathrm{HCl}$ solution, while $\mathrm{Kim}$ et al. ${ }^{3-5}$ found that mechanical rubbing decreases the work function and increases sheet resistance. Also, $\mathrm{HCl}$ treatment should produce some observable change in the work function of ITO according to study of acid treatments performed for several acids by Nüesch et al. ${ }^{15}$ According to results of Fujita $e t$ al., ${ }^{13}$ oxygen plasma treatment results in smoother surface compared to as-received ITO, which is in agreement with results of Kim et al. ${ }^{5}$ However, Kim et al. ${ }^{5}$ have found that oxygen plasma treatment produces smoother surface than mechanical rubbing (both treatments give smoother surface than as-received ITO), while Fujita et al. ${ }^{13}$ obtained opposite result, in addition to enhanced crystallization of TPD grown on oxygen plasma treated ITO. It should be pointed out that increase in the work function similar to that obtained by oxygen plasma treatment can be obtained by UV-ozone treatment. ${ }^{17,20}$ Compared to plasma or chemical treatments, thermal annealing is not an optimal choice for the treatment of ITO. Thermal annealing in vacuum needs to be performed up to high temperatures $\left(\sim 500^{\circ} \mathrm{C}\right)$ to obtain decrease in resisitivity. ${ }^{18}$ Vacuum annealing at $500^{\circ} \mathrm{C}$ removes contamination from the surface and thusly contributes to the increase in the work function. ${ }^{17}$ Annealing in air leads to increase in resistivity, while for annealing in $\mathrm{N}_{2} / \mathrm{H}_{2}$ significant decrease in resistivity can be obtained even at annealing temperatures as low as $200^{\circ} \mathrm{C}{ }^{19}$

In this work, following treatments have been investigated: a) mechanical treatments (mechanical rubbing, followed by ultrasonic bath), b) chemical treatments (dipping into aqueous solutions of various acids, including acids which have not been investigated previously) c) thermal treatments (thermal annealing in different air and nitrogen) d) plasma treatments e) ultraviolet (UV) ozone treatment f) different combinations of the above. We have measured surface sheet resistance of the samples and investigated surface morphology of the treated samples and compared them to "as-received" samples. Several treatments giving best results have been selected to investigate further their influence on the performance of OLEDs. OLEDs have been fabricated using ITO substrates treated with treatments selected, as well as a control OLED fabricated on "as-received" ITO. The impact of ITO treatments on the performance of OLEDs have been investigated on two types of devices, OLEDs with and without transport layer, having the structures glass/ITO/Alq ${ }_{3} / \mathrm{Al}$ and glass/ ITO/TPD/Alq $3 / \mathrm{Al}$, 
respectively, where $\mathrm{Alq}_{3}$ (tris-(8-hydroxyquinoline) aluminum) is emitting layer and TPD (N,N'-diphenyl-N,N'-bis(3methyl-phenyl)-1,1'biphenil-4,4'diamine) is a hole transport layer.

The paper is organized as follows. In the following section, we describe the performed surface treatments and experiments used for characterization of the treated ITO substrates. In Section 3, obtained results are presented and discussed. Finally, conclusions are drawn.

\section{EXPERIMENT}

ITO glass substrates with surface sheet resistance $23.5 \Omega$ /square have been supplied by Varitronix Limited, Hong Kong. The samples have been cut into squares $2 \mathrm{~cm} \times 2 \mathrm{~cm}$. The samples for scanning tunneling microscopy (STM) have been cut into $5 \mathrm{~mm} \times 5 \mathrm{~mm}$ squares. All the substrates have been cleaned prior treatment, first by rubbing with cotton and acetone, then in ultrasonic bath for 10 minutes in acetone, ethanol, and deionized water, respectively, and blow dried in nitrogen.

Acid treatment has been performed by dipping the substrate into aqueous acid solution. The following acids and concentrations were investigated: acetic acid $\mathrm{CH}_{3} \mathrm{COOH}(0.01 \mathrm{M})$, trifluoroacetic acid $\mathrm{CF}_{3} \mathrm{COOH}(0.01 \mathrm{M})$, methane sulfonic acid $\mathrm{CH}_{3} \mathrm{SO}_{3} \mathrm{H}(0.01 \mathrm{M})$, phosphoric acid $\mathrm{H}_{3} \mathrm{PO}_{4}(0.01 \mathrm{M})$, sulphuric acid $\mathrm{H}_{2} \mathrm{SO}_{4}(0.01 \mathrm{M})$, fluoroboric acid $\mathrm{HBF}_{4}(0.01 \mathrm{M})$, and hydrochloric acid $\mathrm{HCl}(30.8 \%)$. The samples were kept in the solution for 5 minutes except in the case of $\mathrm{HCl}$, where due to higher acid concentration treatment lasted 1 minute. Plasma treatment has been performed for ten minutes under pressure $20 \mathrm{~Pa}$ and $\mathrm{DC}$ voltage $500 \mathrm{~V}$. UV ozone treatment has been performed for ten minutes, with $12 \mathrm{~cm}$ distance between $20 \mathrm{~W}$ UV light source and the sample. Thermal annealing has been performed at $200^{\circ} \mathrm{C}$ for two hours in air and 1 $1 / 2$ hour in nitrogen. Mechanical treatment has been performed using clean room wiper rubbing. The samples were ultrasonically cleaned with deionized water after mechanical treatment.

The treated ITO substrates were characterized by measuring sheet resistance and investigating surface morphology. Surface sheet resistance have been determined by four point probe method. STM images have been obtained using Digital Instruments Nanoscope IIIA in STM E-scan with constant current mode. The substrates subjected to different treatments were used to fabricate OLEDs. Two types of devices have been fabricated (OLEDs with and without transport layer), having the structures glass/ITO/Alq $3(100 \mathrm{~nm}) / \mathrm{Al}$ and glass/ ITO/TPD $(60 \mathrm{~nm}) / \mathrm{Alq}_{3}(60 \mathrm{~nm}) / \mathrm{Al}$, respectively, where $\mathrm{Alq}_{3}$ (tris-(8-hydroxyquinoline) aluminum) is emitting layer and TPD (N,N'-diphenyl-N,N'-bis(3-methyl-phenyl)-1,1'biphenil4,4 'diamine) is a hole transport layer. The organic layers have been evaporated in high vacuum. Pressure during evaporation was of the order $10^{-4} \mathrm{~Pa}$. The evaporation rate was $1-2 \AA / \mathrm{s}$. The distance from source to film is about $23 \mathrm{~cm}$ to ensure uniformity of film thickness, and the substrate holder is rotating (rotation speed is 7 revolutions per second). The thickness of the films has been controlled using quartz thickness monitor TM 400, Maxtek Inc. For characterization of fabricated OLEDs, luminance has been measured using LS-100 Minolta luminance meter.

\section{RESULTS AND DISCUSSION}

The results obtained in this work and the results from the literature are summarized in Table I. The work function has been estimated from the tunneling current in STM measurement. The effect of the work function on the tunneling current at barrier width $s$ is determined by: ${ }^{21}$

$$
\frac{I\left(\varphi_{1}, s\right)}{I\left(\varphi_{2}, s\right)}=\exp \left[-\frac{4 \pi s \sqrt{2 m}}{h}\left(\sqrt{\varphi_{1}}-\sqrt{\varphi_{2}}\right)\right],
$$

where $m$ is the electron mass and $h$ is the Planck constant, and $\varphi_{1}$ and $\varphi_{2}$ are the work functions of materials compared. If we assume that the work function of untreated ITO is $4.5 \mathrm{eV}$ (most commonly obtained value in the literature), ${ }^{5,14,20}$ we can deduce the change in the work function induced by a surface treatment. Fig. 1 shows STM images of a) Untreated ITO b) air plasma treated ITO c) oxygen plasma treated ITO d) $\mathrm{CF}_{3} \mathrm{COOH}$ treated ITO e) $\mathrm{CH}_{3} \mathrm{COOH}$ treated ITO f) $\mathrm{HBF}_{4}$ treated ITO g) $\mathrm{H}_{3} \mathrm{PO}_{4}$ treated ITO h) $\mathrm{H}_{2} \mathrm{SO}_{4}$ treated ITO i) $\mathrm{HCl}$ treated ITO j) mechanically treated ITO. It can be observed that the mechanical rubbing produces the smoothest surface, with root mean square surface roughness equal $0.07 \mathrm{~nm}$. This is in agreement with the results of Fujita $e t$ al. ${ }^{13}$ who also obtained very smooth surface with mechanical rubbing but detected no change in the work function. Kim et al. ${ }^{5}$ have observed decrease in the work function after mechanical rubbing, slight 
decrease in surface roughness, and small increase in sheet resistance. The increase in sheet resistance is in agreement with our results, but we have obtained increase in the work function and significantly smoother surface.

Table I Properties of ITO for different surface treatments

\begin{tabular}{|c|c|c|c|}
\hline Surface treatment & Sheet resistance $(\Omega /)$ & Work function $(\mathrm{eV})$ & Surface roughness (nm) \\
\hline as-received & $\begin{array}{l}\text { 11.2, 14.8 Ref. }{ }^{3,4} \\
\text { 16.1 Ref. } \\
\text { 35 } \text { Ref. }^{15} \\
\sim 10 \text { Ref. }^{14} \\
\leq 20 \text { Ref. }^{10} \\
\text { 100 Ref. }{ }^{17} \\
\text { 23.5 this work }\end{array}$ & $\begin{array}{l}4.1 \text { Ref. }^{12} \\
\text { 5.15 } \text { Ref. }^{9} \\
4.5 \text { Ref. }^{14} \\
4.4 \text { Ref. }^{15} \\
4.5 \text { Ref. }^{5} \\
4 \text { Ref. }^{17} \\
4.5 \text { Ref. }^{20}\end{array}$ & $\begin{array}{c}2.6 \text { Ref. }^{5} \\
2.9 \text { this work }\end{array}$ \\
\hline mechanical rubbing & $\begin{array}{c}16.3 \text { (paper) }^{\text {Ref. }}{ }^{5} \\
16.5 \text { (teflon) Ref. } \\
26.6 \text { this work }\end{array}$ & $\begin{array}{l}4.2{\text { (paper) } \text { Ref. }^{5}} \\
4.2 \text { (teflon) Ref. }^{5} \\
4.71 \text { this work }^{\circ}\end{array}$ & $\begin{array}{c}2.3 \text { Ref. }^{5} \\
2.4 \text { Ref. }^{5} \\
0.07 \text { this work }\end{array}$ \\
\hline Ar plasma & 16.7/17.3/17.0 Ref. $^{5}$ & $\begin{array}{l}\text { 4.2 } \text { Ref. }^{12} \\
\text { 5.16 Ref. } \\
4.3 \text { Ref. }^{14} \\
4.5 \text { Ref. }^{5} \\
4.3 \text { Ref. }^{20}\end{array}$ & 10.9/15.4/23.0 Ref. $^{5}$ \\
\hline oxygen plasma & $\begin{array}{c}16.4 / 15.0 / 16.4 \text { Ref. }^{5} \\
9.9,9.6 \text { Ref. }^{3,4} \\
22.9 \text { this work }\end{array}$ & $\begin{array}{c}4.35 / 4.75 / 4.65 \text { Ref. }^{5} \\
4.7 \text { Ref }^{12} \\
4.55 \text { this work }\end{array}$ & $\begin{array}{c}1.4 / 1.4 / 2.1 \text { Ref. }^{5} \\
1.9 \text { this work }\end{array}$ \\
\hline $\mathrm{Ar} / 50 \% \mathrm{O}_{2}$ plasma & & 6 Ref. $^{14}$ & \\
\hline air plasma & & $\begin{array}{c}\text { 5.44 Ref. }{ }^{9} \\
5.36 \text { this work }\end{array}$ & 2.3 this work \\
\hline $\mathrm{H}_{3} \mathrm{PO}_{4}$ & 27.3 this work & $\begin{array}{c}5.1 \text { Ref. }^{15} \\
4.87 \text { this work }\end{array}$ & 1.7 this work \\
\hline $\mathrm{HPF}_{6}$ & & 4.8 Ref. $^{15}$ & \\
\hline $\mathrm{HNO}_{3}$ & & 4.5 Ref. $^{15}$ & \\
\hline $\mathrm{NaOH}$ & & 4.2 Ref. $^{15}$ & \\
\hline $\mathrm{N}\left(\mathrm{C}_{4} \mathrm{H}_{9}\right)_{4} \mathrm{OH}$ & & 3.9 Ref. $^{15}$ & \\
\hline aquaregia & $\begin{array}{l}\text { 18.5/23.5/28.6 } \text { Ref. }^{5} \\
28.8,22.2 \text { Ref. }^{3,4}\end{array}$ & 4.6/4.3/4.7 Ref. $^{5}$ & $3.8 / 8.4 / 8.8 \operatorname{Ref}^{f}$ \\
\hline aquaregia/oxygen plasma & $\begin{array}{c}27.7 \text { Ref. }^{5} \\
21.7,19.6 \text { Ref. }^{3,4}\end{array}$ & 4.6 Ref. $^{5}$ & 6.0 Ref. $^{5}$ \\
\hline oxygen plasma/aquaregia & $\begin{array}{c}>30.0 \text { Ref. }^{5} \\
\text { 29.1, 26.4 Ref. }\end{array}$ & 4.7 Ref. $^{5}$ & 1.8 Ref. $^{5}$ \\
\hline RCA & 19.6 Ref. $^{5}$ & 4.35 Ref. $^{5}$ & 3.4 Ref. $^{5}$ \\
\hline UV ozone & 22.5 this work & $\begin{array}{l}\sim 5.1 \text { Ref. }^{17} \\
4.75 \text { Ref. }^{20}\end{array}$ & \\
\hline annealing & $\begin{array}{l}\text { in air, at } 200^{\circ} \mathrm{C}, 22.4 \text { this work } \\
\text { in } \mathrm{N}_{2} \text {, at } 200^{\circ} \mathrm{C}, 23.2 \text { this work }\end{array}$ & $\left(\right.$ at $500^{\circ} \mathrm{C}$ ) $4.25 \mathrm{eV} \mathrm{Ref.} .^{17}$ & \\
\hline $\mathrm{CH}_{3} \mathrm{COOH}$ & 23.6 this work & 4.76 this work & 2.4 this work \\
\hline $\mathrm{CF}_{3} \mathrm{COOH}$ & 23.2 this work & 4.89 this work & 2.2 this work \\
\hline $\mathrm{CH}_{3} \mathrm{SO}_{3} \mathrm{H}$ & 24.1 this work & & \\
\hline $\mathrm{H}_{2} \mathrm{SO}_{4}$ & 24.7 this work & 4.66 this work & 1.3 this work \\
\hline $\mathrm{HBF}_{4}$ & 24.8 this work & 4.66 this work & 1.2 this work \\
\hline $\mathrm{HCl}$ & 26.3 this work & 4.54 this work & 1.3 this work \\
\hline $\mathrm{H}_{3} \mathrm{PO}_{4} / \mathrm{UV}$ ozone & 22.8 this work & & \\
\hline $\mathrm{CF}_{3} \mathrm{COOH} / \mathrm{UV}$ ozone & 22.7 this work & & \\
\hline $\mathrm{H}_{2} \mathrm{SO}_{4} / \mathrm{UV}$ ozone & 23.3 this work & & \\
\hline $\mathrm{HCl} / \mathrm{UV}$ ozone & 28.4 this work & & \\
\hline UV ozone/ $/ \mathrm{H}_{3} \mathrm{PO}_{4}$ & 23.0 this work & & \\
\hline UV ozone/ $/ \mathrm{CF}_{3} \mathrm{COOH}$ & 23.8 this work & & \\
\hline UV ozone $/ \mathrm{H}_{2} \mathrm{SO}_{4}$ & 23.2 this work & & \\
\hline UV ozone/HCl & 40.0 this work & & \\
\hline
\end{tabular}




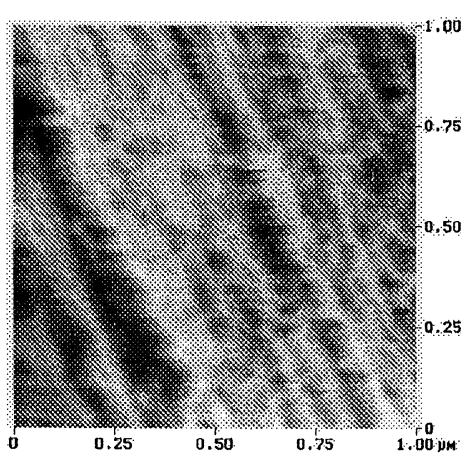

a)

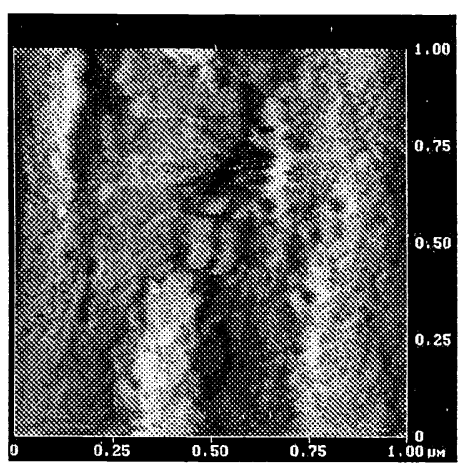

d)

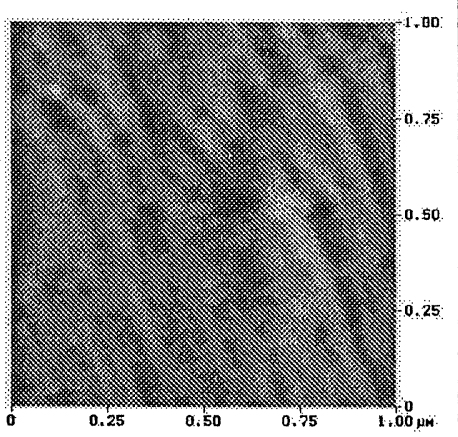

g)

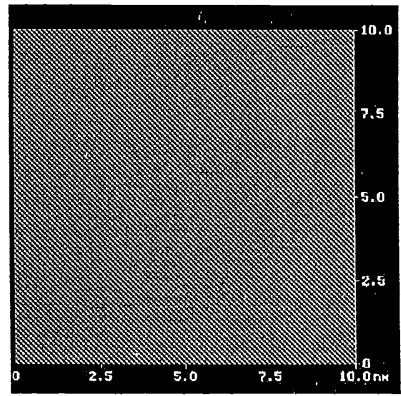

j)

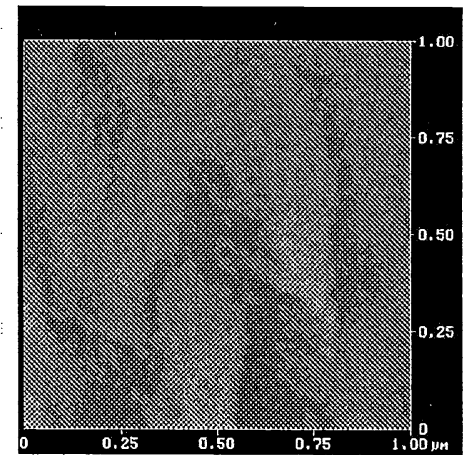

b)

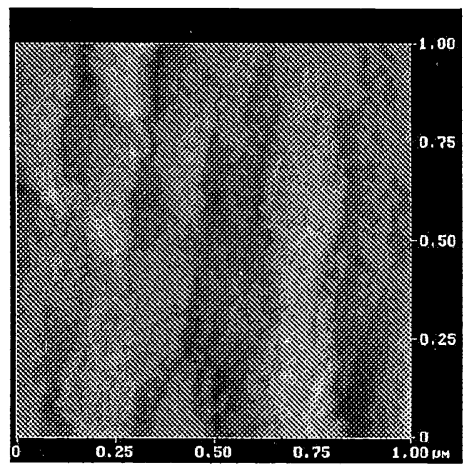

e)

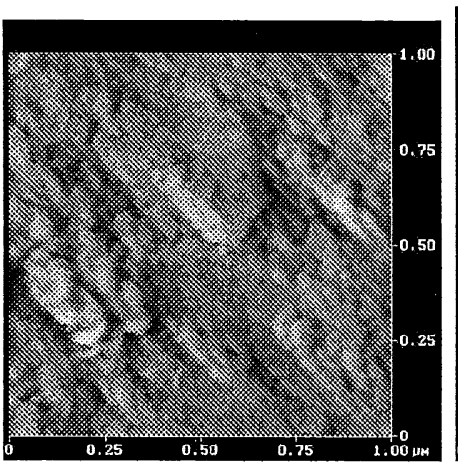

h)

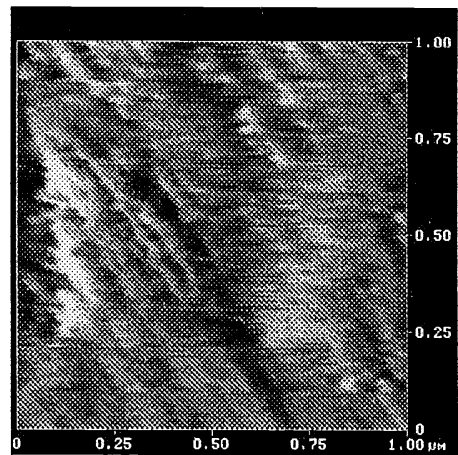

c)

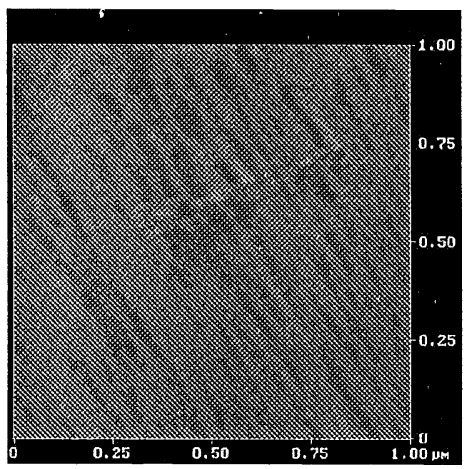

f)

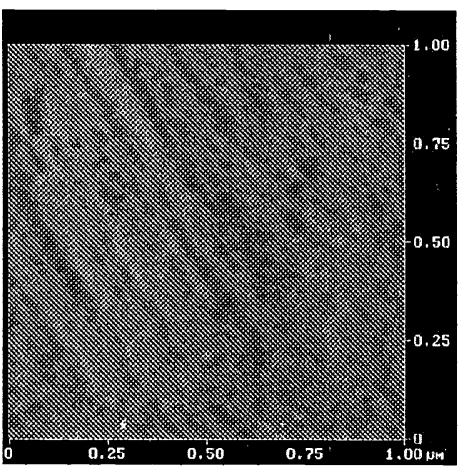

i)

Fig. 1 STM images of a) Untreated ITO b) air plasma treated ITO c) oxygen plasma treated ITO d) $\mathrm{CF}_{3} \mathrm{COOH}$ treated ITO e) $\mathrm{CH}_{3} \mathrm{COOH}$ treated ITO f) $\mathrm{HBF}_{4}$ treated ITO g) $\mathrm{H}_{3} \mathrm{PO}_{4}$ treated ITO h) $\mathrm{H}_{2} \mathrm{SO}_{4}$ treated ITO i) $\mathrm{HCl}$ treated ITO j) mechanically treated ITO. 


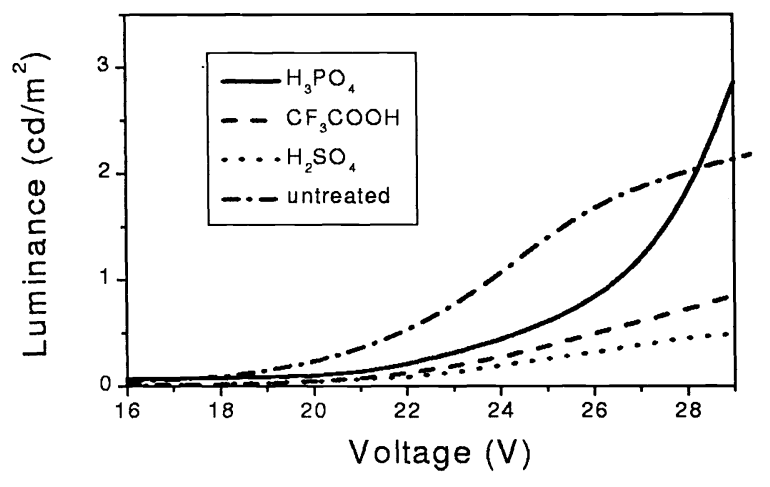

Figure 2 Luminance vs. voltage for ITO/ $\mathrm{Alq}_{3} / \mathrm{Al}$ OLEDs, for different treatments of ITO surface. For all three cases, UV ozone treatment has been performed prior to acid treatment. Dash-dot line denotes untreated ITO, solid line denotes UV ozone $+\mathrm{H}_{3} \mathrm{PO}_{4}$ treated ITO, dashed line denotes $\mathrm{UV}$ ozone $+\mathrm{CF}_{3} \mathrm{COOH}$ treated ITO, and dotted line denotes UV ozone $+\mathrm{H}_{2} \mathrm{SO}_{4}$ treated ITO.

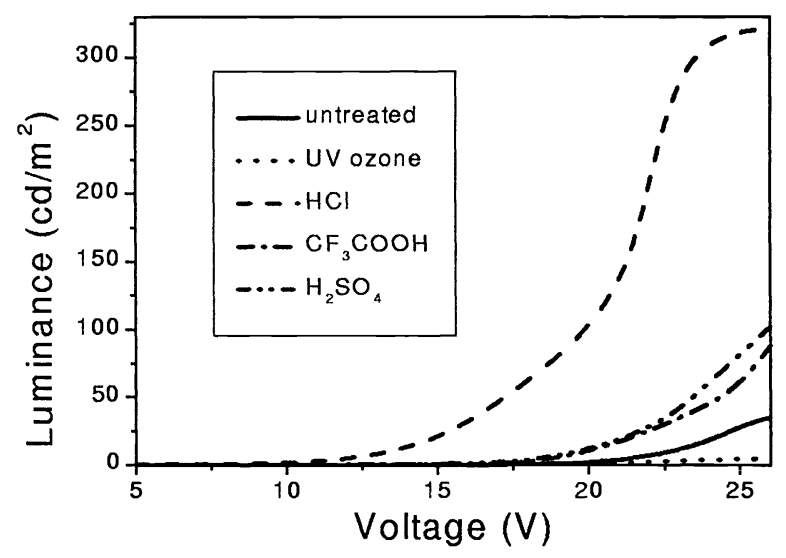

Figure 3 Luminance vs. voltage for ITO/ $\mathrm{Alq}_{3} / \mathrm{Al}$ OLEDs, for different treatments of ITO surface. For all three cases, UV ozone treatment has been performed prior to acid treatment. Solid line denotes untreated ITO, dashed line denotes UV ozone+HCl treated sample, dotted line denotes UV ozone treated ITO, dashed-dot-dot line denotes UV ozone $+\mathrm{H}_{2} \mathrm{SO}_{4}$ treated ITO

All acid treatments except $\mathrm{CF}_{3} \mathrm{COOH}$ cause increase in the surface sheet resistance, and all acids cause increase in the work function and decrease in the surface roughness. Combinations of acid treatments and UV ozone reduce sheet resistance, except in the case of $\mathrm{HCl}$ and $\mathrm{UV}$ ozone combination treatment. In order to investigate the influence of the UV ozone+acid combination treatment, we have fabricated two types of devices: OLEDs with and without transport layer, having the structures glass/ITO/Alq $3 / \mathrm{Al}$ and glass/ ITO/TPD/Alq $3 / \mathrm{Al}$. For single layer devices, only UV ozone $+\mathrm{H}_{3} \mathrm{PO}_{4}$ treatment results in better performance compared to the OLED fabricated on untreated ITO substrate. For two layer devices, UV ozone $+\mathrm{HCl}$ treated one exhibits significantly better performance compared to other devices. For $\mathrm{UV}$ ozone $+\mathrm{H}_{3} \mathrm{PO}_{4}$ treated substrate, the light emission is uneven (there exist very bright small regions embedded in dimly lit surface) and device is burnt out at much lower voltage. This is probably due to non-uniform hole injection. Fujita et al. ${ }^{13}$ have concluded that oxygen plasma treatment causes enhanced crystallization of TPD layer, and this effect, together with non uniformity of layer thickness, may contribute to uneven luminescence and low breakdown voltage. All other acids in combination with UV ozone treatment improve the device performance. The most significant improvement has been obtained for UV ozone + $\mathrm{HCl}$ treated ITO, which surprisingly results in the highest sheet resistance. Mechanical treatment improves the stability of the device, though luminance is lower compared to untreated ITO. This is in agreement with results of Fujita et al. ${ }^{13}$ Therefore, there exists complex dependence of the device performance on the ITO substrate, sheet resistance and surface roughness, and it would be difficult to define simple guidelines concerning these parameters which would result in the best device performance. Furthermore, optimal ITO treatment is device structure dependent, i.e. different treatments produce the best results for single layer and two layer OLEDs. 


\section{CONCLUSION}

We have investigated a) mechanical treatments (mechanical rubbing, followed by ultrasonic bath), b) chemical treatments (dipping into aqueous solutions of various acids, including acids which have not been investigated previously) c) thermal treatments (thermal annealing in different atmospheres) d) plasma treatments e) UV ozone treatment f) different combinations of the above. We have measured surface sheet resistance of the samples and investigated surface morphology of the treated samples and compared them to "as-received" samples. The lowest surface roughness is obtained by mechanical rubbing, the highest work function by air plasma treatment, and the lowest sheet resistance by UV ozone treatment and thermal annealing in air at $200^{\circ} \mathrm{C}$. We have selected several treatments giving best results. Then we have fabricated OLEDs using ITO substrates treated with treatments selected, as well as a control OLED fabricated on "asreceived" ITO. The impact of ITO treatments on the performance of OLEDs have been investigated on two types of devices, OLEDs with and without transport layer, having the structures glass/ITO/Alq ${ }_{3} / \mathrm{Al}$ and glass/ ITO/TPD/Alq $/ \mathrm{Al}$, respectively, where $\mathrm{Alq}_{3}$ (tris-(8-hydroxyquinoline) aluminum) is emitting layer and TPD (N,N'-diphenyl-N,N'-bis(3-methyl-phenyl)1,1 'biphenil-4,4'diamine) is a hole transport layer. The best device performance has been obtained for two layer OLED grown on UV ozone $+\mathrm{HCl}$ treated ITO substrate.

\section{ACKNOWLEDGEMENTS}

The authors would like to thank the RGC earmarked grant of Hong Kong and the University of Hong Kong CRCG research grant for financial support. The authors would like to thank Dr. G. K. Y. Chan and Ms. Crystal Cheung from the Department of Chemistry, the University of Hong Kong for performing STM measurements.

\section{REFERENCES}

1. B. Choi, H. Yoon, and H. H. Lee, "Surface treatment of indium tin oxide by $\mathrm{SF}_{6}$ plasma for organic light-emitting diodes",Appl. Phys. Lett., vol. 76, pp. 412-414, Jan. 2000.

2. J. S. Kim, R. H. Friend, and F. Cacialli, "Surface energy and polarity of treated indium-tin-oxide anodes for polymer light-emitting diodes studied by contact-angle measurements", J. Appl. Phys. vol. 86, pp. 2774-2778, Sept. 1999.

3. J. S. Kim, F. Cacialli, A. Cola, G. Gigli, and R. Cingolani, "Increase of charge carriers density and reduction of Hall mobilities in oxygen-plasma treated indium-tin-oxide surfaces", Appl. Phys. Lett. vol . 75, pp. 19-21, July 1999.

4. J. S. Kim, F. Cacialli, A. Cola, G. Gigli, and R. Cingolani, "Hall measurements of treated indium tin oxide surfaces", Synthetic Metals. vol . 111-112, pp. 363-367, 2000.

5. J. S. Kim, M. Granström, R. H. Friend, N. Johanson, W. R. Salaneck, and F. Cacialli, "Indium-tin-oxide treatments for single- and double-layer polymeric light-emitting diodes: The relation between the anode physical, chemical, and morphological properties and the device performance”, J. Appl. Phys. Vol. 84, pp. 6859-6870, Dec. 1998.

6. J. S. Kim, P. K. H. Ho, D. S. Thomas, R. H. Friend, F. Cacialli, G. W. Bao, and S. F. Y. Li, "X-ray photoelectron spectroscopy of surface-treated indium-tin-oxide thin films", Chem. Phys. Lett. vol. 315, pp. 307- 312, 1999.

7. J. S. Kim, F. Cacialli, M. Granström, R. H. Friend, N. Johansson, W. R. Salaneck, R. Daik, and W. J. Feast, "Characterization of the properties of surface-treated indium-tin-oxide thin films", Synthetic Metals vol. 101, pp. 111$112,1999$.

8. J. S. Kim, F. Cacialli, R. H. Friend, R. Daik, and W. J. Feast, "Electroluminescence lifetime and efficiency of polymer LEDs with surface-treated anodes, Synthetic metals vol. 102, pp. 1065-1066, 1999.

9. K. Furukawa, Y. Terasaka, H. Ueda, and M. Matsumura, "Effect of a plasma treatment of ITO on the performance of organic electroluminescent devices", Synthetic Metals vol. 91, pp. 99- 101, 1997.

10. F. Steuber, J. Staudigel, M. Stössel, and J. Simerer,"Reduced operating voltage of organic electroluminescent devices by plasma tratment of the indium tin oxide anode", Appl. Phys. Lett. vol. 74, pp. 3558- 3560, June 1999.

11. S. Major, S. Kumar, M. Bhatnayar, and K. L. Chopra, "Effect of hydrogen plasma treatment on transparent conducting oxides", Appl. Phys. Lett. vol. 49, pp. 394-396, Aug. 1986.

12. D. J. Miliron, I. G. Hill, C. Shen, A. Khan, and J. Schwartz, "Surface oxidation activates indium tin oxide for hole injection", J. Appl. Phys. Vol. 87, pp. 572-576, Jan. 2000.

13. S. Fujita, T. Sakamoto, K. Ueda, K. Ohta, and S. Fujita, " Surface treatments of indium-tin-oxide substrates and its effects on initial nucleation processes of diamine films”, Jpn. J. Appl. Phys. Vol. 36, pp. 350-353, Jan. 1997. 
14. M. Ishii, T. Mori, H. Fujikawa, S. Tokito, and Y. Taga, "Improvement of organic electroluminescent devices performance by in situ plasma treatment of indium-tin-oxide surface", J. Luminescence vol. 87-89, pp. 1165-1167, 2000.

15. F. Nüesch, L. J. Rothberg, E. W. Forsythe, Q. T. Le, and Y. Gao, "A photoelectron study on the indium tin oxide treatment by acids and bases'. Appl. Phys. Lett. vol. 74, pp. 880-882, Feb. 1999.

16. F. Nüesch, E. W. Forsythe, Q. T. Le, Y. Gao, and J. Rothberg, "Importance of indium tin oxide surface acido basicity for charge injection into organic materials based light emitting diodes", J. Appl. Phys. Vol. 87, pp. 7973-7980, June 2000.

17. M. G. Mason, L. S. Hung, C. W. Tang, S. T. Lee, K. W. Wang, and M. Wang, "Characterization of treated indium-tinoxide surfaces used in electroluminescent devices", J. Appl. Phys. vol. 86, pp. 1688-1692, Aug. 1999.

18. H. Morikawa and M. Fujita, "Crystallization and decrease in resistivity on heat treatment of amorphous indium tin oxide films prepared by d.c. magnetron sputtering", Thin Solid Films vol. 339, pp. 309-313, 1999.

19. D. V. Morgan, Y. H. Aliyu, R. W. Bunce, and A. Salehi, "Annealing effects on opto-electronic properties of sputtered and thermally evaporated indium-tin-oxide films", Thin Solid Films vol. 312, pp. 268- 2721998.

20. K. Sugiyama, H. Ishii, Y. Ouchi, and K. Seki, "Dependence of indium-tin-oxide work function on surface cleaning method as studied by ultraviloet and x-ray photoemission spectroscopies", J. Appl. Phys. vol. 87, pp. 295-298, Jan. 2000.

21. A. A. Marchenko, V. V. Cherepanov, D. T. Tarashchenko, Z. I. Kazantseva, and A. G. Naumovets, "A low work function substrate for STM studies of objects with poor tunneling transparency: lanthanium hexaboride (100)", Surf. Sci. vol. 416, pp. 460-465 (1998). 